$\begin{array}{ll}\text { Research Square } & \begin{array}{l}\text { Preprints are preliminary reports that have not undergone peer review. } \\ \text { They should not be considered conclusive, used to inform clinical practice, } \\ \text { or referenced by the media as validated information. }\end{array}\end{array}$

\title{
The effectiveness and safety of D2 plus para-aortic lymphadenectomy for resectable gastric cancer: a systematic review and meta-analysis
}

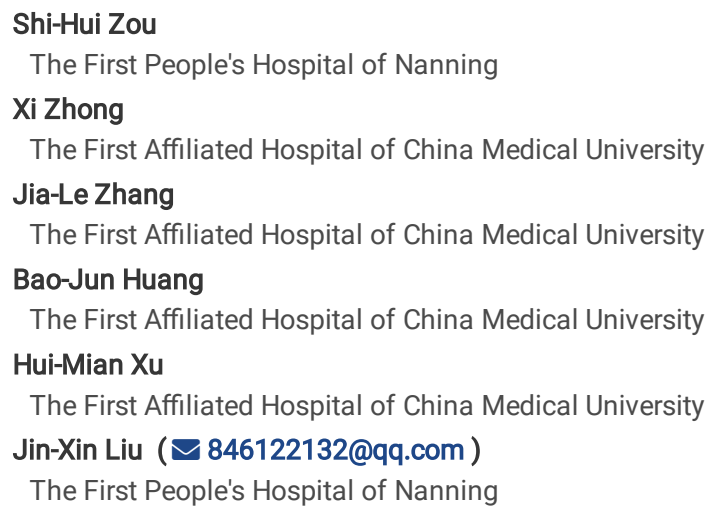




\section{Abstract}

Background: Gastric cancer (GC) is among the malignant tumors of highest morbidity and mortality in the world, and has a profile of high lymph node metastasis rate. Lymph node clearance is a critical part of gastric cancer surgery, however, the extent of lymph node clearance, for example, whether to perform abdominal aortic lymph node dissection, remains considerably controversial. In this study, we performed a systematic review and meta-analysis to assess the effects of D2 plus para-aortic lymphadenectomy (PALD) on survival and postoperative complications in patients with GC.

Methods: An electronic search was conducted through PubMed, Embase and cochrane library. The Q test and $\mathrm{I}^{2}$ were used to assess heterogeneity. The publication bias was evaluated via funnel plots. All statistical analyses were performed using STATA 14.0 (STATA, College Station, TX).

Results: 908 studies were retrieved via literature search and eight studies were finally included. There was no significant difference between D2 and D2+PALD in the 5-year survival rate after surgery (HR: $\left.1.00,95 \% \mathrm{Cl}: 0.97-1.03, \mathrm{P}=0.897 ; \mathrm{I}^{2}=64.9 \%\right)$. Besides, the 30 -day mortality (RR: $1.17,95 \% \mathrm{Cl}$ : $0.66-2.10, \mathrm{P}=0.590$; $\mathrm{I}^{2}=0.0 \%$ ) and the overall risk of postoperative complications (RR: $1.15,95 \% \mathrm{Cl}: 0.83-1.59, \mathrm{P}=0.411 ; \mathrm{I}^{2}=35.5 \%$ ) were comparable between $\mathrm{D} 2$ and $\mathrm{D} 2+\mathrm{PALD}$.

Conclusion: Based on current literature body, compared with D2, D2+PALD does not prevail in terms of long-term survival or perioperative outcomes.

\section{Background}

Gastric cancer (GC) is among the malignant tumors of highest morbidity and mortality in the world. More than 1 million new cases along with an estimated 783,000 deaths (equivalent to one twelfth of all-cause death worldwide) were reported in 2018, making GC the fifth leading cause of cancer incidence and third of cancer-related death ${ }^{1,2}$. The high-risk regions of gastric cancer are mainly in East Asia, namely China, South Korea and Japan ${ }^{3-5}$. Due to mild and atypical clinical manifestations and signs in earlier stage, GC patients are usually diagnosed in advanced stage, leading to poor prognosis ${ }^{6,7}$. The therapeutic strategies of GC mainly including surgery, radiotherapy, chemotherapy, etc., among which surgical treatment is especially important. Gastrectomy plus secondstage lymph node dissection (D2) has become a standard curative procedure for advanced GC in East Asian countries, especially in Japan ${ }^{8,9}$.

Five-year survival rates and postoperative complications are well-recognized indicators that are robust to assess the efficacy and safety of surgery. Lymph node metastasis can occur in the early stage of GC, for advanced GC patients, the risk is even higher, so lymph node dissection is particularly critical in GC surgery. However, the extent of lymph node clearance, for example, whether to perform abdominal aortic lymph node dissection, remains considerably controversial. According to the $4^{\text {th }}$ edition of Japanese Gastric Cancer Treatment Guidelines, for the tumor not invading esophagus, the removal of lymph nodes in the D2 lymphadenectomy for total gastrectomy includes No. 1-7, 8a, 9, 11p, 11d and 12a lymph nodes ${ }^{9}$. The removal of lymph nodes in the D2 plus para-aortic lymphadenectomy (PALD) including D2 lymphadenectomy plus No. 16 lymph node. Studies have shown that more than $20 \%$ of patients with advanced gastric cancer have No. 16 lymph node metastasis ${ }^{10,11}$. Some researchers believe that D2+PALD can extract more lymph nodes than traditional D2, achieving better therapeutic effects and improving patient survival ${ }^{12-14,3,15-17}$. On the contrary, some researchers believe that D2+PALD can lead to greater trauma, higher blood transfusion rates, longer operative time and hospital stay, etc., without increasing the patient's five-year survival rate ${ }^{18-22}$. In this study, we evaluated existing literature and conducted a systematic review meta-analysis to compare the clinical effects of the two procedures.

\section{Materials And Methods}

Literature and search strategy

Databases such as PubMed, Embase, and Cochrane library database were independently searched by two authors to identify original articles published until the end of June, 2019, using the following terms: "gastric", "stomach", "cancer", "tumor", "malignancy", "neoplasm", "para-aortic", "D3", "D4", and "lymphadenectomy".. Manual screening of references was also conducted. No language restriction was performed.

Study selection

This meta-analysis is performed in accordance with the Preferred Reporting Items for Systematic Reviews and Meta-analysis (PRISMA) ${ }^{23}$. The inclusion and exclusion criteria for this meta-analysis were as follows: (1) All patients underwent radical gastrectomy with pathological diagnosis of primary GC. (2) Patients with distant metastasis, residual GC, severe cardiovascular, respiratory, liver or renal function diseases were excluded. (3) There should be sufficient data, including survival rate, postoperative complications, etc., and studies with inadequate data were excluded. (4) Data and related results can be extracted directly or indirectly from the original study. Conference abstracts and reports were excluded due to incomplete information. (5) Only comparable original articles were included, excluding reviews, systematic reviews and meta-analyses, letter to editor, case reports, and single-arm studies. The study selection process was conducted by two independent reviewers in accordance with the following procedure: the retrieved literature were firstly reviewed via title and abstract screening, the remaining were then scrutinized by full-text.

\section{Data extraction and quality assessment}

The following data were independently extracted by two authors: first author, year of publication, country, study period, sample size, age, TNM stage, abdominal aortic lymph node condition, type of surgery, time of surgery, intraoperative blood loss, blood transfusion, postoperative complications, postoperative mortality and survival data. The Newcastle-Ottawa quality assessment scale (NOS) was used to evaluate the methodological quality of the included studies ${ }^{24}$. According to the evaluation criteria of the NOS scale, studies with more than 5 points were judged as moderate quality studies, while studies with 7 or more points were considered high quality studies. 
Continuous data were processed using weighted mean difference (WMD) and 95\% Confidence interval (CI), and postoperative complications and survival relative risk (RR) or risk ratio (HR) and $95 \% \mathrm{Cl}$. Quantitative syntheses were conducted using random effects model to provide more conservative results, considering the inevitable heterogeneity. Cochran Q test and $P^{2}$ statistic were used to quantify and evaluate study heterogeneity. $P^{2} 50 \%$ and/or $P<0.1$ indicate significant statistical heterogeneity 25,26 . Heterogeneity was detected by sensitivity analysis. Publication bias was evaluated via funnel plots. Since the number of studies included in each meta-analysis is less than 10, funnel plots, instead of Egger's test, were used to assess publication bias, considering the lack of statistical power ${ }^{27}$. All statistical analyses were performed using Stata 14.0 software (Stata Corporation, College Station, TX USA). P<0.05 was considered to be statistically significant.

\section{Results}

Search results and study characteristics

The flow chart of the literature search is shown in Figure 1. Based on a predefined search strategy, 908 studies were initially identified through database and manual search. After excluding duplicates, screening title and abstracts, 879 unrelated studies were excluded and the remaining 29 studies were further evaluated by full-text view. Among these 29 studies, 21 articles were excluded due to incomplete information or other reasons. In the end, the meta-analysis included eight eligible studies, all of which were retrospective observational cohort studies $28,18,29,3,30,20,19,31$.

All included studies were published between 2003 and 2014, with sample sizes ranging from 117 to 1792. Among these studies, three were from Japan, four from China, and one from Poland. According to the results of NOS assessment, among the eight studies, two with eight and three with seven were considered of high-quality, the remaining three scored six points and were deemed moderate-quality. The detailed baseline characteristics of all included studies are summarized in Table 1.

Impact of D2+PALD on long-term survival of GC patients

We first evaluated the effect of D2+PALD on 5-year survival. A total of seven studies were pooled. The results showed no significant difference between the two groups (HR: 1.00, 95\% Cl: 0.97-1.03, $P=0.897 ; P=64.9 \%$ ) (Fig. 2). No significant asymmetry was observed in funnel plot.

Impact of D2+PALD on perioperative outcomes of GC patients

Mortality analysis within 30 days after surgery revealed no significant difference between the mortality of the two groups. D2+PALD did not dramatically increase postoperative mortality within 30 days (RR: $1.17,95 \% \mathrm{Cl}: 0.66-2.10, P=0.590 ; R=0.0$ ) (Table 2 ). In addition, a summary of complications showed that D2+PALD did not significantly increase the overall risk of postoperative complications (RR: $1.15,95 \% \mathrm{Cl}: 0.83-1.59, P=0.411 ; P=35.5 \%)($ Figure 3 ), including abdominal infection, anastomotic leakage, pancreatic fistula, and pulmonary infection, no significant difference between the two groups (Table 2). No significant asymmetry was observed in funnel plots of each quantitative syntheses.

\section{Publication bias}

According to the results of the funnel plot observation, there is no significant publication bias in this study.

\section{Discussion}

Surgical treatment is the only way to achieve radical cure for resectable $\mathrm{GC}^{32}$, and has been significantly improved through decades of development. The Japan Gastric Cancer Association was the first to define the three stations of GC in 1998, and defined the terminology of the operations as D1, D2, and D3 according to the range of lymph nodes in the operation ${ }^{33}$, and updated the lymph node dissection range of GC according to the extent of gastric resection in $2011^{34,35}$. Wu et al published a study comparing D1 and D2 in 2006, and the results showed that the 5-year survival rates of patients with advanced GC after D1 and D2 were 53.6\% and 59.5\%, respectively ( $\mathrm{P}=0.041)$. Compared with D1 surgery, patients with advanced GC undergoing D2 surgery achieved better survival outcome ${ }^{36}$. Plenty of retrospective studies have shown that $\mathrm{D} 2$ resection can improve survival in patients with higher $\mathrm{T} \& \mathrm{~N}-\mathrm{staged}$ tumors, and in this regard, D2 surgery has been widely used to treat advanced GC in Asia ${ }^{37-43}$

Controversy lies in whether to perform D2 or D2+ PALD surgery on patients with advanced GC ${ }^{44}$. According to relevant studies, once gastric tumors invade the subserosal (T3 phase), serosal (T4a phase) or adjacent structures (T4b phase), the metastatic risk of para-aortic lymph nodes (PANs) increases to 10\% to $30 \%{ }^{45-47}$. PALD may help to remove potential metastases, and in the meantime, surely help to collect more lymph nodes, which is critical to staging and prognosis prediction ${ }^{48-50}$. Maeta et al reported that a patient with pathological PAN metastases survived more than 80 months after systemic PALD ${ }^{46}$. Park et al found that the median overall survival of patients with isolated PAN metastases was significantly longer than that of patients with single organ metastases other than PAN or multiple organ metastases ${ }^{51}$. Tokunaga et al retrospectively analyzed 178 patients with pathologically positive PAN who underwent radical resection and observed a 5 -year survival rate of $13.0 \% 52$. Fujiwara et al performed preoperative chemotherapy on 20 patients who had no other non-cure factors other than PALN metastasis and had a good clinical response to induction chemotherapy. After D2+PALD treatment, the 3-year and 5-year survival rates were increased to $72 \%$ and $65 \%$, respectively ${ }^{15}$. Fushida et al studied 24 patients with GC who were diagnosed with PAN metastasis, all patients underwent D2+PALD and the prognosis was good ${ }^{53}$. Tokunaga et al retrospectively studied the role of D3 lymphadenectomy in 173 patients, suggesting that D3 resection may be beneficial for selected PAN-positive patients without other incurable factors ${ }^{52}$. However, Hu et al showed that D2 plus PALD was not 
significantly superior, survival-wise, to D2 in patients with T3-4, N2 staging ${ }^{18}$. Besides, Sasako et al showed that D2 lymphadenectomy plus prophylactic PALD did not improve the survival rate of curable GC compared with D2 lymphadenectomy, even though D2+PALD did not increase the risk of anastomotic leakage, pancreatic fistula, and abdominal infection ${ }^{28}$. In line with the conclusion of the work by Sasako et al, the results of our comprehensive analysis on prophylactic and therapeutic D2+PALD showed that, compared with D2, D2+PALD did not improve the patients' long-term survival, but nonetheless, did not increase the risk of postoperative complications.

It is well known that D2+PALD is more difficult to perform than D2, with longer operative time, more bleeding, and longer hospital stays, requiring experienced surgeons ${ }^{18,3}$. However, with the development of modern technology, the extensive use of advanced medical equipment has reduced the operation time, operative mortality and surgery-related morbidity. D2+PALD can also perform as safely as D2 in professional medical centers with well-trained surgeons ${ }^{45}$.

Several limitations reside in our work. First, all the included studies are retrospective, which affects the level of evidence of this study to some extent. Second, we only focused on overall survival as efficacy outcome in this study, other outcomes like recurrence free survival and rate of recurrence were not covered due to lack of data. Third, we were unable to access the personalized data of included studies to perform any further analyses to adjust for confounding factors. Fourth, the surgical results are closely related to the surgeon's experience. The expertise and approach of surgeons differs and matters, in which resides heterogeneity ${ }^{54}$. Fifth, the postoperative intervention, such as postoperative radiotherapy and chemotherapy, on the patients also has a great impact on the outcome, however, due to the lack of relevant data, we did not account for this confounding factor. Sixth, the number of studies included is relatively small, especially for the studies concerning therapeutic D2+PALD, which might affect the credibility of the results of the analyses concerning long-term survival and perioperative complications. Besides, the lack of comparable studies on therapeutic D2+PALD makes it impossible to draw a conclusion, in this regard, more elaborately designed multi-center studies with larger sample size are needed in the future to illuminate the advantages and disadvantages of D2+PALD more comprehensively.

\section{Conclusion}

In summary, D2 + PALD can be as safe as standard D2, but requires experienced surgeons to operate. Prophylactic D2 + PALD did not increase postoperative complications compared to standard D2, but no long-term survival benefit was achieved. The role of therapeutic D2 + PALD requires more researches to further confirm. More well-designed multi-center studies of larger scale are needed in the future to explore D2 + PALD.

\section{Declarations}

\section{Acknowledgements}

Not applicable.

\section{Authors' contributions}

Shi-Hui Zou contributed to acquisition and analysis of data, the design and concept of the work, and drafted the manuscript. Jin-Xin Liu contributed to the conception, analysis and revisions of the work. Hui-Mian Xu and Bao-Jun Huang contributed to analysis, interpretation and revisions of the work. Jia-Le Zhang contributed to the conception, acquisition, analysis and interpretation of data and revisions of the work. All authors approve of the final version of the manuscript.

\section{Disclosure of interest}

The authors report no conflict of interest.

\section{Funding}

No funding available for this study.

\section{Data availability statement}

The authors confirm that the data supporting the finding of this this study are available within the article.

\section{References}

1. Bray F, Ferlay J, Soerjomataram I, Siegel RL, Torre LA, Jemal A. Global cancer statistics 2018: GLOBOCAN estimates of incidence and mortality worldwide for 36 cancers in 185 countries. CA Cancer J Clin. 2018;68(6):394-424. doi:10.3322/caac.21492.

2. Guggenheim DE, Shah MA. Gastric cancer epidemiology and risk factors. J Surg Oncol. 2013;107(3):230-6. doi:10.1002/jso.23262.

3. Zhang CH, He YL, Schwarz RE, Smith DD, Wang L, Liu FK et al. Evaluation of para-aortic nodal dissection for locoregionally advanced gastric cancer with 1-3 involved para-aortic nodes. Chinese medical journal. 2014;127(3):435-41. doi:10.3760/cma.j.issn.0366-6999.20130664.

4. Chen W, Zheng R, Baade PD, Zhang S, Zeng H, Bray F et al. Cancer statistics in China, 2015. CA Cancer J Clin. 2016;66(2):115-32. doi:10.3322/caac.21338.

5. Kim HS, Yi SY, Jun HJ, Lee J, Park JO, Park YS et al. Clinical outcome of gastric cancer patients with bone marrow metastases. Oncology. 2007;73(34):192-7. doi:10.1159/000127386. 
6. Zhao B, Zhang J, Zhang J, Zou S, Luo R, Xu H et al. The Impact of Preoperative Underweight Status on Postoperative Complication and Survival Outcome of Gastric Cancer Patients: A Systematic Review and Meta-analysis. Nutr Cancer. 2018;70(8):1254-63. doi:10.1080/01635581.2018.1559937.

7. Song Z, Wu Y, Yang J, Yang D, Fang X. Progress in the treatment of advanced gastric cancer. Tumour Biol. 2017;39(7):1010428317714626. doi:10.1177/1010428317714626.

8. Kodera Y, Sasako M, Yamamoto S, Sano T, Nashimoto A, Kurita A et al. Identification of risk factors for the development of complications following extended and superextended lymphadenectomies for gastric cancer. Br J Surg. 2005;92(9):1103-9. doi:10.1002/bjs.4979.

9. Japanese Gastric Cancer A. Japanese gastric cancer treatment guidelines 2014 (ver. 4). Gastric Cancer. 2017;20(1):1-19. doi:10.1007/s10120-016-0622-4.

10. Takashima S, Kosaka T. Results and controversial issues regarding a para-aortic lymph node dissection for advanced gastric cancer. Surg Today. 2005;35(6):425-31. doi:10.1007/s00595-004-2976-1.

11. Isozaki H, Okajima K, Fujii K, Nomura E, Izumi N, Mabuchi H et al. Effectiveness of paraaortic lymph node dissection for advanced gastric cancer. Hepatogastroenterology. 1999;46(25):549-54.

12. Sano T, Sasako M, Yamamoto S, Nashimoto A, Kurita A, Hiratsuka M et al. Gastric cancer surgery: morbidity and mortality results from a prospective randomized controlled trial comparing D2 and extended para-aortic lymphadenectomy-Japan Clinical Oncology Group study 9501 . Journal of clinical oncology. 2004;22(14):2767-73. doi:10.1200/JC0.2004.10.184.

13. Yonemura Y, Wu CC, Fukushima N, Honda I, Bandou E, Kawamura T et al. Metastasis in para-aortic lymph nodes in patients with advanced gastric cancer, treated with extended lymphadenectomy. Hepato-gastroenterology. 2007;54(74):634-8.

14. Shimoyama S, Mafune K, Kaminishi M. Safety of a paraaortic node dissection for selected advanced gastric cancer patients. Hepato-gastroenterology. 2005;52(65):1631-5.

15. Fujiwara Y, Omori T, Demura K, Miyata H, Sugimura K, Ohue M et al. A Multidisciplinary Approach for Advanced Gastric Cancer with Paraaortic Lymph Node Metastasis. Anticancer research. 2015;35(12):6739-45.

16. Oyama K, Fushida S, Kinoshita J, Makino I, Nakamura K, Hayashi H et al. Efficacy of pre-operative chemotherapy with docetaxel, cisplatin, and S-1 (DCS therapy) and curative resection for gastric cancer with pathologically positive para-aortic lymph nodes. Journal of Surgical Oncology. 2012;105(6):535-41. doi:10.1002/jso.22125.

17. Takeda J, Koufuji K, Kodama I, Tsuji Y, Maruiwa M, Kawabata S et al. Para-aortic lymph node dissection for the treatment of advanced gastric cancer. The Kurume medical journal. 1993;40(3):101-6.

18. Hu JK, Yang K, Zhang B, Chen XZ, Chen ZX, Chen JP. D2 plus para-aortic lymphadenectomy versus standardized D2 lymphadenectomy in gastric cancer surgery. Surgery today. 2009;39(3):207-13. doi:10.1007/s00595-008-3856-X.

19. Yonemura Y, Wu CC, Fukushima N, Honda I, Bandou E, Kawamura T et al. Randomized clinical trial of D2 and extended paraaortic lymphadenectomy in patients with gastric cancer. Int J Clin Oncol. 2008;13(2):132-7. doi:10.1007/s10147-007-0727-1.

20. Kulig J, Popiela T, Kolodziejczyk P, Sierzega M, Szczepanik A, Polish Gastric Cancer Study G. Standard D2 versus extended D2 (D2+) lymphadenectomy for gastric cancer: an interim safety analysis of a multicenter, randomized, clinical trial. American journal of surgery. 2007;193(1):10-5.

doi:10.1016/j.amjsurg.2006.04.018.

21. Bencivenga M, Verlato G, Giacopuzzi S, Di Cosmo M, Cipollari C, Marrelli D et al. Survival benefit of superextended (D3) lymphadenectomy in subgroups of patients with advanced gastric cancer. European Journal of Surgical Oncology. 2014;40(11):S36. doi:10.1016/j.ejso.2014.08.068.

22. Morita S, Fukagawa T, Fujiwara $\mathrm{H}$, Katai $\mathrm{H}$. The clinical significance of para-aortic nodal dissection for advanced gastric cancer. European Journal of Surgical Oncology. 2016;42(9):1448-54. doi:10.1016/j.ejso.2016.01.002.

23. Moher D, Liberati A, Tetzlaff J, Altman DG, Group P. Preferred reporting items for systematic reviews and meta-analyses: the PRISMA statement. Int J Surg. 2010;8(5):336-41. doi:10.1016/j.ijsu.2010.02.007.

24. Stang A. Critical evaluation of the Newcastle-Ottawa scale for the assessment of the quality of nonrandomized studies in meta-analyses. Eur J Epidemiol. 2010;25(9):603-5. doi:10.1007/s10654-010-9491-z.

25. DerSimonian R, Laird N. Meta-analysis in clinical trials. Control Clin Trials. 1986;7(3):177-88.

26. Higgins JP, Thompson SG, Deeks JJ, Altman DG. Measuring inconsistency in meta-analyses. BMJ. 2003;327(7414):557-60. doi:10.1136/bmj.327.7414.557.

27. Palma Perez S, Delgado Rodriguez M. [Practical considerations on detection of publication bias]. Gac Sanit. 2006;20 Suppl 3:10-6.

28. Sasako M, Sano T, Yamamoto S, Kurokawa Y, Nashimoto A, Kurita A et al. D2 lymphadenectomy alone or with para-aortic nodal dissection for gastric cancer. New England Journal of Medicine. 2008;359(5):453-62. doi:10.1056/NEJMoa0707035.

29. Zhang Y, Tian S. Does D2 plus para-aortic nodal dissection surgery offer a better survival outcome compared to D2 surgery only for gastric cancer consistently? A definite result based on a hospital population of nearly two decades. Scandinavian journal of surgery. 2013;102(4):251-7. doi:10.1177/1457496913491343.

30. Zhan WH, He YL, Zheng ZQ, Peng JS, Cai SR, Ma JP. Effectiveness of para-aortic lymph node dissection for advanced gastric cancer. Zhonghua wai ke za zhi [Chinese journal of surgery]. 2003;41(5):375-8.

31. Kunisaki C, Akiyama H, Nomura M, Matsuda G, Otsuka Y, Ono H et al. Comparison of surgical results of D2 versus D3 gastrectomy (para-aortic lymph node dissection) for advanced gastric carcinoma: a multi-institutional study. Ann Surg Oncol. 2006;13(5):659-67. doi:10.1245/ASO.2006.07.015.

32. McCulloch P. The role of surgery in patients with advanced gastric cancer. Best Pract Res Clin Gastroenterol. 2006;20(4):767-87. doi:10.1016/j.bpg.2006.03.006. 
33. Japanese Gastric Cancer A. Japanese Classification of Gastric Carcinoma - 2nd English Edition. Gastric Cancer. 1998;1(1):10-24. doi:10.1007/s101209800016.

34. Japanese Gastric Cancer A. Japanese gastric cancer treatment guidelines 2010 (ver. 3). Gastric Cancer. 2011;14(2):113-23. doi:10.1007/s10120-0110042-4.

35. Sano T, Aiko T. New Japanese classifications and treatment guidelines for gastric cancer: revision concepts and major revised points. Gastric Cancer. 2011;14(2):97-100. doi:10.1007/s10120-011-0040-6.

36. Wu CW, Hsiung CA, Lo SS, Hsieh MC, Chen JH, Li AF et al. Nodal dissection for patients with gastric cancer: a randomised controlled trial. The Lancet Oncology. 2006;7(4):309-15. doi:10.1016/S1470-2045(06)70623-4.

37. Pacelli F, Doglietto GB, Bellantone R, Alfieri S, Sgadari A, Crucitti F. Extensive versus limited lymph node dissection for gastric cancer: a comparative study of 320 patients. Br J Surg. 1993;80(9):1153-6. doi:10.1002/bjs.1800800930.

38. Volpe CM, Koo J, Miloro SM, Driscoll DL, Nava HR, Douglass HO, Jr. The effect of extended lymphadenectomy on survival in patients with gastric adenocarcinoma. J Am Coll Surg. 1995;181(1):56-64.

39. Harrison LE, Karpeh MS, Brennan MF. Extended lymphadenectomy is associated with a survival benefit for node-negative gastric cancer. Journal of gastrointestinal surgery. 1998;2(2):126-31.

40. Onate-Ocana LF, Aiello-Crocifoglio V, Mondragon-Sanchez R, Ruiz-Molina JM. Survival benefit of D2 lympadenectomy in patients with gastric adenocarcinoma. Ann Surg Oncol. 2000;7(3):210-7.

41. Kasakura Y, Mochizuki F, Wakabayashi K, Kochi M, Fujii M, Takayama T. An evaluation of the effectiveness of extended lymph node dissection in patients with gastric cancer: a retrospective study of 1403 cases at a single institution. J Surg Res. 2002;103(2):252-9. doi:10.1006/jsre.2002.6368.

42. Edwards P, Blackshaw GR, Lewis WG, Barry JD, Allison MC, Jones DR. Prospective comparison of D1 vs modified D2 gastrectomy for carcinoma. Br J Cancer. 2004;90(10):1888-92. doi:10.1038/sj.bjc.6601790.

43. Mogal H, Fields R, Maithel SK, Votanopoulos K. In Patients with Localized and Resectable Gastric Cancer, What is the Optimal Extent of Lymph Node Dissection-D1 Versus D2 Versus D3? Ann Surg Oncol. 2019. doi:10.1245/s10434-019-07417-5.

44. Douridas GN, Pierrakakis SK. Is There Any Role for D3 Lymphadenectomy in Gastric Cancer? Frontiers in surgery. 2018;5:27. doi:10.3389/fsurg.2018.00027.

45. Roviello F, Pedrazzani C, Marrelli D, Di Leo A, Caruso S, Giacopuzzi S et al. Super-extended (D3) lymphadenectomy in advanced gastric cancer. Eur J Surg Oncol. 2010;36(5):439-46. doi:10.1016/j.ejso.2010.03.008.

46. Maeta M, Yamashiro H, Saito H, Katano K, Kondo A, Tsujitani S et al. A prospective pilot study of extended (D3) and superextended para-aortic lymphadenectomy (D4) in patients with T3 or T4 gastric cancer managed by total gastrectomy. Surgery. 1999;125(3):325-31.

47. de Manzoni G, Di Leo A, Roviello F, Marrelli D, Giacopuzzi S, Minicozzi AM et al. Tumor site and perigastric nodal status are the most important predictors of para-aortic nodal involvement in advanced gastric cancer. Ann Surg Oncol. 2011;18(8):2273-80. doi:10.1245/s10434-010-1547-5.

48. Smith DD, Schwarz RR, Schwarz RE. Impact of total lymph node count on staging and survival after gastrectomy for gastric cancer: data from a large USpopulation database. Journal of clinical oncology. 2005;23(28):7114-24. doi:10.1200/JC0.2005.14.621.

49. Gholami S, Janson L, Worhunsky DJ, Tran TB, Squires MH, 3rd, Jin LX et al. Number of Lymph Nodes Removed and Survival after Gastric Cancer Resection: An Analysis from the US Gastric Cancer Collaborative. J Am Coll Surg. 2015;221(2):291-9. doi:10.1016/j.jamcollsurg.2015.04.024.

50. Yoshikawa T, Sasako M, Sano T, Nashimoto A, Kurita A, Tsujinaka T et al. Stage migration caused by D2 dissection with para-aortic lymphadenectomy for gastric cancer from the results of a prospective randomized controlled trial. British journal of surgery. 2006;93(12):1526-9. doi:10.1002/bjs.5487.

51. Park IH, Kim SY, Kim YW, Ryu KW, Lee JH, Lee JS et al. Clinical characteristics and treatment outcomes of gastric cancer patients with isolated para-aortic lymph node involvement. Cancer Chemother Pharmacol. 2011;67(1):127-36. doi:10.1007/s00280-010-1296-y.

52. Tokunaga M, Ohyama S, Hiki N, Fukunaga T, Aikou S, Yamaguchi T. Can superextended lymph node dissection be justified for gastric cancer with pathologically positive para-aortic lymph nodes? Ann Surg Oncol. 2010;17(8):2031-6. doi:10.1245/s10434-010-0969-4.

53. Fushida S, Oyama K, Kinoshita J, Ninomiya I, Ohta T. Significance of para-aortic lymph node dissection for advanced gastric cancer patients following DCS therapy. Annals of Oncology. 2016;27:ix71-ix2. doi:10.1093/annonc/mdw582.009.

54. Lee JH, Ryu KW, Lee JH, Park SR, Kim CG, Kook MC et al. Learning curve for total gastrectomy with D2 lymph node dissection: cumulative sum analysis for qualified surgery. Ann Surg Oncol. 2006;13(9):1175-81. doi:10.1245/s10434-006-9050-8.

\section{Tables}


Table 1. The characteristics of included studies.

\begin{tabular}{|c|c|c|c|c|c|c|c|c|c|c|}
\hline author & Country & Year & Sample size & $\begin{array}{l}\text { TNM } \\
\text { stage }\end{array}$ & $\begin{array}{c}\text { Involvement } \\
\text { of Para- } \\
\text { aortic } \\
\text { lymph node }\end{array}$ & $\begin{array}{l}\text { Post-operative } \\
\text { mortality }(\mathrm{P} / \mathrm{S})\end{array}$ & $\begin{array}{c}\text { Survival } \\
\text { data (5-year } \\
\text { OS, P vs S) }\end{array}$ & $\begin{array}{c}\text { Anastomic } \\
\text { leakage }(\mathrm{P} / \mathrm{S})\end{array}$ & $\begin{array}{l}\text { Pancreatic } \\
\text { fistula(P/S) }\end{array}$ & $\begin{array}{r}\mathrm{Pu} \\
\text { diso }\end{array}$ \\
\hline Sasako et & Japan & 2008 & 523ロ260/263ם & T2b,T3,T4 & $\mathrm{N}$ & $0.8 \% / 0.8 \%$ & $70.3 \% / 69.2 \%$ & $1.9 \% / 2.3 \%$ & $6.2 \% / 5.3 \%$ & 1.5 \\
\hline $\mathrm{Hu}$ et al. & China & 2009 & 117ロ62/55ロ & T1, T2, & NR & $0 \% / 1.8 \%$ & $65.8 \% / 66.1 \%$ & NR & NR & 3. \\
\hline Zhang et & China & 2013 & $1792 \square 448 / 1344 \square$ & T1, T2, & NR & $2 \% / 2 \%$ & $31.2 \% / 26.6 \%$ & $2 \% / 2 \%$ & NR & \\
\hline Zhang et & China & 2014 & 157ロ69/88ロ & pT3,pT4 & $\mathrm{Y}$ & $0 / 0$ & $43.7 \% / 31.8 \%$ & $1.4 \% / 1.1 \%$ & $2.9 \% / 2.3 \%$ & \\
\hline Zhan et & China & 2003 & 153ロ73/85ロ & II, III/IV & NR & $0 / 0$ & $46 \% / 27 \%$ & $0 / 0$ & $0 / 0$ & \\
\hline Kulig et & Poland & 2007 & $275 \square 134 / 141 \square$ & T1, T2, T3 & $\mathrm{N}$ & $2.2 \% / 4.9 \%$ & & $3.7 \% / 6.4 \%$ & $0.7 \% / 1.4 \%$ & \\
\hline Yonemura & Japan & 2007 & 269ロ134/135ם & $\mathrm{T} 2, \mathrm{~T} 3, \mathrm{~T} 4$ & $\mathrm{~N}$ & $3.7 \% / 0 \%$ & $55 \% / 52.6 \%$ & NR & NR & \\
\hline $\begin{array}{l}\text { Kunisaki } \\
\text { et al. }\end{array}$ & Japan & 2006 & 580ロ150/430ロ & $\mathrm{T} 2, \mathrm{~T} 3, \mathrm{~T} 4$ & NR & $0.67 \% / 0.23 \%$ & $50.4 \% / 56 \%$ & $6 \% / 2.8 \%$ & $10.8 \% / 8.7 \%$ & 12. \\
\hline
\end{tabular}

Abbreviations: P: D2+PALD; PALD: Para-aortic lymph node dissection; S: Stand D2; OS: Overall survival; NR: Not reported; N: No; Y: Yes.

\section{Figures}

\section{Flow diagram}

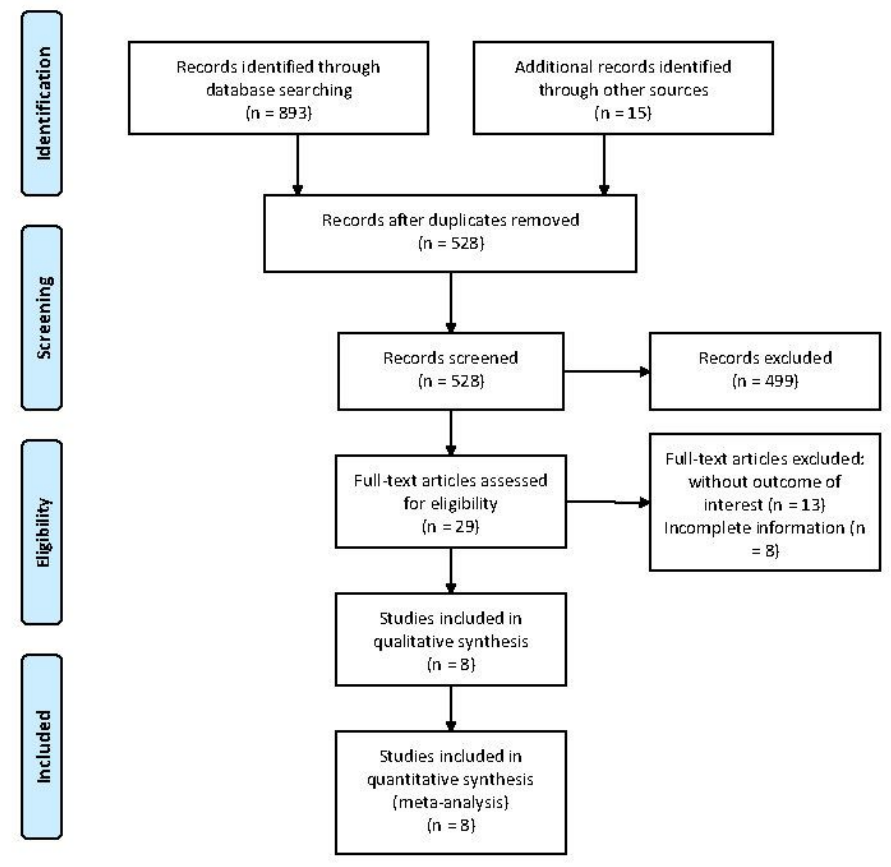

\section{Figure 1}

The flow diagram of study selection. 


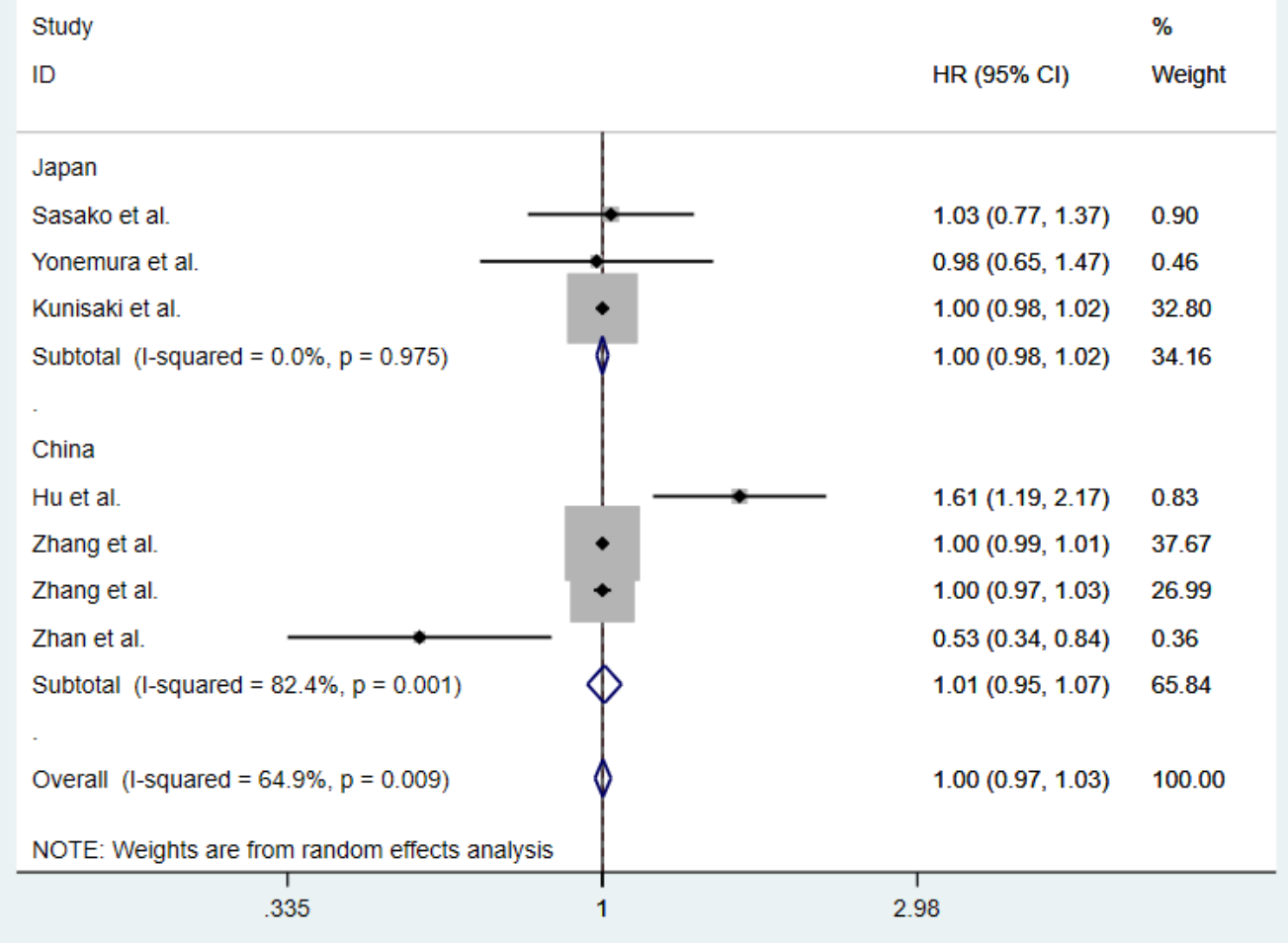

Figure 2

Forest plots evaluating the impact of D2+PALD on long-term survival.

study

Weight

Sasako et al.
Hu et al.
Zhang et al.
Kulig et al.
Overall (l-squared $=35.5 \%, p=0.199)$

\section{Figure 3}

Forest plots evaluating the impact of D2+PALD on postoperative complications. 


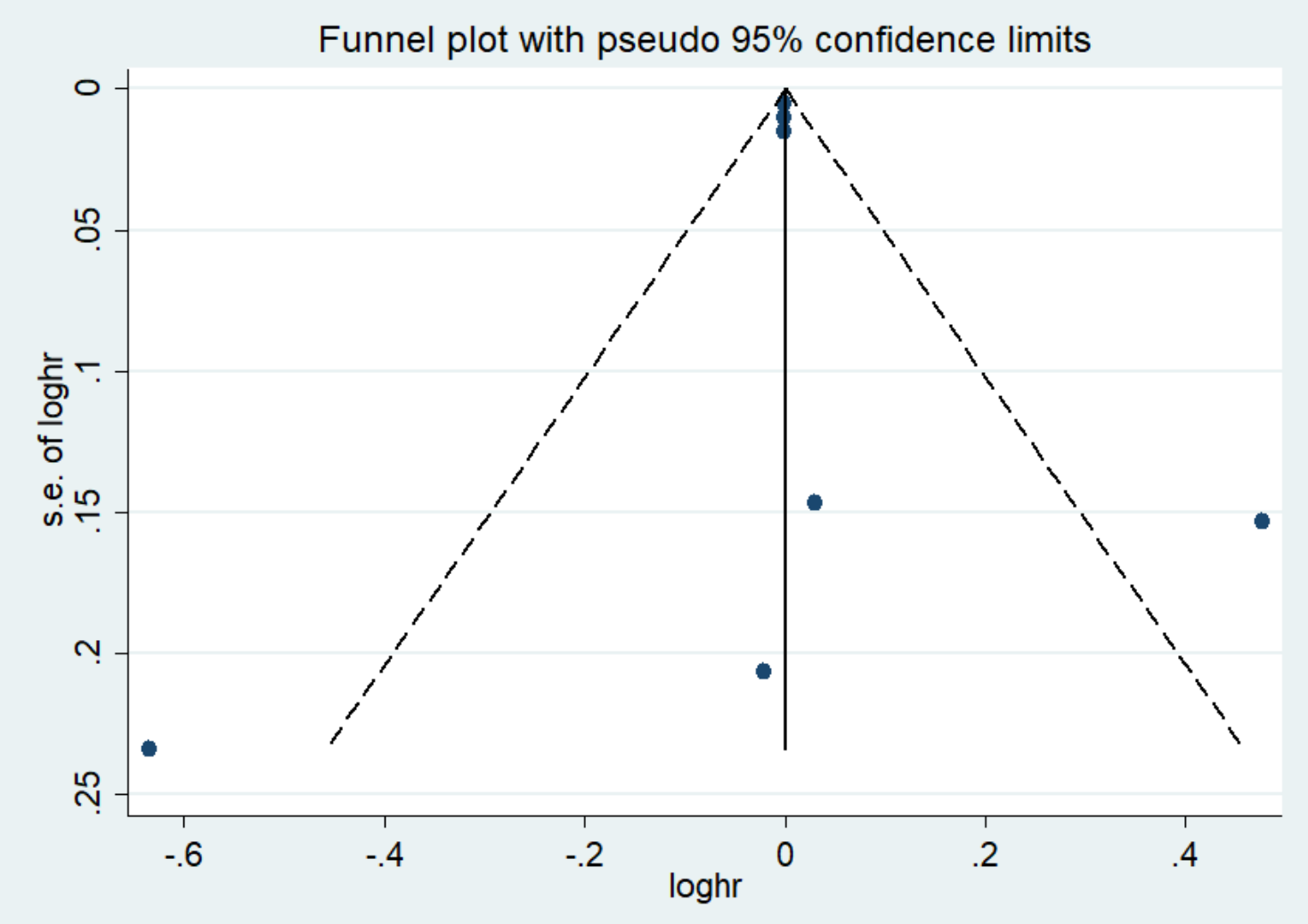

Figure 4

Funnel plot for the analysis of long-term survival. 